\title{
Horizontal annular flow through orifice studied by X-ray microtomography
}

\author{
Paul Porombka $^{1}$ (D) . Stephan Boden ${ }^{1}$ (D) . Dirk Lucas ${ }^{1}$ (D) . Uwe Hampel ${ }^{1}$ (D
}

Received: 9 June 2020 / Revised: 26 October 2020 / Accepted: 28 October 2020 / Published online: 23 December 2020

(c) The Author(s) 2020

\begin{abstract}
An X-ray microtomography $(\mu \mathrm{CT})$ system was adapted so that 3D scans of fixed horizontal or vertical test sections can be performed. The mobile $\mu \mathrm{CT}$ system has been applied to measure the local, time-averaged volume fraction distribution of developing annular air-water flow in a horizontal pipe with $\mu \mathrm{m}$ spatial resolution. Based on the volume fraction data the liquid film thickness profile is computed and the accumulation, stripping and renewal of the annular liquid film at a circular orifice is studied. The development length of the annular flow downstream of the orifice is evaluated based on the integral volume fraction and the change of the film thickness profile along the pipe axis. Both parameters give a consistent result, indicating that liquid film renewal can be judged based on integral measurement techniques in this case. Further, the detailed 3D data enables the validation of computational fluid dynamics codes based on phase-averaged variables such as the EulerEuler approach.
\end{abstract}

\section{Graphic abstract}

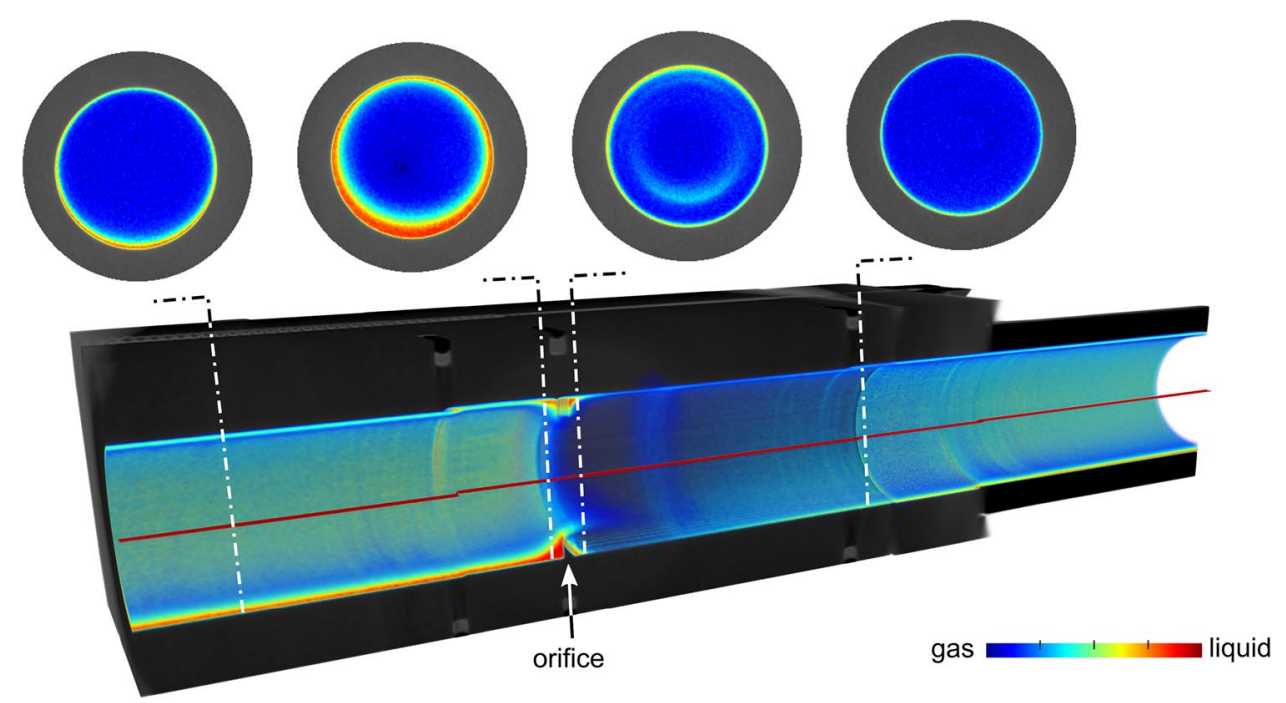

Keywords X-ray microtomography · Film thickness · Circular orifice · Annular flow

\section{Latin letters}

A

$D$

Paul Porombka

p.porombka@hzdr.de

$1 \quad$ Helmholtz-Zentrum Dresden-Rossendorf e.V., Bautzner Landstraße 400, 01328 Dresden, Germany

$\begin{array}{ll}f_{h} & \text { Probability density function of film height } \\ & {\left[\mathrm{m}^{-1}\right]} \\ g & \text { Gravitational acceleration }\left[\mathrm{kg} \mathrm{m} \mathrm{s}^{-2}\right] \\ h & \text { Instantaneous film thickness }[\mathrm{m}] \\ H & \text { Mean film thickness }[\mathrm{m}] \\ K=U_{\mathrm{G}} / U_{\mathrm{L}} & \text { Velocity ratio } \\ \dot{M} & \text { Mass flow rate }\left[\mathrm{kg} \mathrm{s}^{-1}\right]\end{array}$




$\begin{array}{ll}R & \text { Pipe radius }[\mathrm{m}] \\ R e & \text { Reynolds number based on superficial } \\ & \text { velocity }[-] \\ r & \text { Radial coordinate }[\mathrm{m}] \\ U & \text { Bulk velocity }\left[\mathrm{m} \mathrm{s}^{-1}\right] \\ x, y, z & \text { Cartesian coordinates }[\mathrm{m}] \\ \dot{x} & \text { Mass dryness fraction }[-]\end{array}$

Greek letters

$\alpha \quad$ Volume fraction [-]

$\delta \quad$ Dimensionless film thickness [-]

$\lambda \quad$ Free-mean-path length through the pipe of the transmitting radiation [-]

$\mu \quad$ Attenuation coefficient $\left[\mathrm{m}^{-1}\right]$

$\varphi \quad$ Polar angle [rad]

$\rho \quad$ Density $\left[\mathrm{kg} / \mathrm{m}^{3}\right]$

$\sigma \quad$ Orifice area ratio $A_{\min } / A_{\max }[-]$

$\tau \quad$ Time interval of measurement [s]

\section{Indices and superscripts}

$\begin{array}{ll}\mathrm{G} & \text { Gas } \\ \mathrm{k} & \text { Phase index } \\ \mathrm{L} & \text { Liquid } \\ \mathrm{rms} & \text { Root-mean-square } \\ \mathrm{S} & \text { Superficial } \\ \phi^{\prime} & \text { Normalized variable }\end{array}$

\section{Introduction}

Horizontal two-phase flows occur in a variety of industrial applications, e.g. pipeline transportation of oil and gas, apparatuses in the chemical industry, direct steam generation solar power plants and heat exchangers. The heat and mass transfer in such processes is closely related to the spatial gas and liquid phase distribution. Consider for example the steam condensation or flow boiling in pipes where the wall heat flux decreases when a closed liquid or gas film is formed, respectively. Furthermore, the reaction rates in chemical reactors can vary considerably, depending on whether homogeneous or heterogeneous mixture of the gas and liquid phases is present. For the design of such industrial-scale process equipment, flow simulation methods based on phase-averaged variables-such as the two-fluid model-are increasingly popular as they promise three-dimensional flow information at relatively low computational cost. While these methods are often well validated against analytical or academic test cases, validation data for two-phase flow in non-trivial geometries is rarely available. This work tries to bridge this gap by applying tomographic measurement techniques to obtain volume fraction and film thickness distribution in horizontal annular flow through a circular orifice, which is frequently encountered in process equipment at high mass flux conditions.

Early experimental investigations of annular flow used quick closing valves to measure the integral liquid holdup in a pipe section (Govier et al. 1957). At the same time, radiation methods were also used in pioneering works to measure the liquid holdup non-intrusively, e.g. gamma-ray densitometry (Hooker and Popper 1958). They are still frequently used today (Perera 2018). Further, radiographic techniques are also applied to 2D multiphase flow visualization and allow investigation of high-speed transient phenomena when using high-intensity synchrotron radiation (Karathanassis et al. 2018). To measure local phase distribution in annular flow needle probes (Butterworth 1972; Fukano and Ousaka 1987) are widely applied to the liquid film whereas sampling probes (Gill 1963; Butterworth 1972) are used to measure the core liquid fraction distribution. Miniature wire-mesh sensors enable instantaneous measurement of 2D cross-sectional liquid fraction profiles (Hampel 2009). Techniques to measure film thickness in macro- and micro-scale systems are reviewed by Tibiriçá et al. (2010). Furthermore, nonintrusive optical techniques have been developed based on light reflection (Shedd and Newell 1998) or induced fluorescence (Hewitt et al. 1964) which have been continuously developed until today (Cherdantsev 2019). All of these methods can provide localized data of volume fraction, film thickness or entrained droplet fraction, however their application is limited to relatively simple geometries.

Therefore, investigations on two-phase flow through circular orifices mainly focus on measurement (McNeil 2000) or simulation (Roul and Dash 2012) of the pressure drop across the restriction. Averaged void fractions at different axial positions have been measured in slug/plug flows using ring-type impedance (Fossa and Guglielmini 2002) or capacitance (Almalki and Ahmed 2020) sensors. In horizontal annular flow, void fraction distributions have been measured in cross sections using optical probes (Salcudean et al. 1983). For the vertical case, mean minimum film thickness (Sekoguchi 1978) and mean film flowrate (McQuillan and Whalley 1984) have been measured along axial positions using spatially integrating techniques.

As local measurement techniques are unsuitable to scan large volumes, tomographic techniques have been applied to annular two-phase flow since the $80 \mathrm{~s}$. Tomographic measurements are particularly suitable for validation of phase averaged simulation methods as they measure the statistical average liquid fractions. A comprehensive review of the state of the art in X-ray CT for multiphase flows was given by Heindel (2011). More recently, (Katono 2014) and (Maurer 2015) presented three dimensional X-ray CT systems that are capable of measuring volume fraction distributions in vertical multiphase flows. Apart from X-rays, different radiation types have been used including gamma rays (Bieberle 
2013), and cold neutrons (Zboray et al. 2018). Previous works at Helmholtz-Zentrum Dresden-Rossendorf (HZDR) have applied 3D X-ray tomography techniques to multiphase flows in chemical reactors (Boden et al. 2008) and in horizontal pipes (Bieberle et al. 2020). The current work is part of that ongoing development process.

In microfocus $\mathrm{CT}(\mu \mathrm{CT})$ applications, to obtain projections from different sides, the object of interest is usually rotated between a fixed source/detector pair. This was demonstrated for vertical multiphase flows such as cavitating nozzle flow (Lorenzi 2017) or Taylor bubbles (Boden et al. 2017). However, horizontal two-phase flows cannot be rotated around the pipe axis. Consequently, a high precision rotating source/detector arrangement is required in this case to match the spatial resolution of the $\mu \mathrm{CT}$ system. In this work, a mobile and tiltable $\mu \mathrm{CT}$ system is presented that overcomes these limitations.

\section{Experimental setup}

\subsection{Air-water flow loop}

The experimental setup as shown in Fig. 1a consists of an open air and closed water loop feeding a horizontal acrylic pipe test section. The air mass flow from the pressurized air tank to the mixing section is controlled by one of two differential pressure mass flow controllers. Deionized water is pumped from a separator tank by a geared pump through a Coriolis type mass flow meter to the transparent mixing section depicted in Fig. 1b, which has the same diameter as the test section. The water is injected to the air stream via eight hollow-cone spray nozzles generating an annular-mist flow at mixer outlet due to impinging droplets on the pipe wall. Following the test section the two-phase mixture flows through a large-diameter flexible hose to a separator tank where the air is vented to the ambience. The air-water flow in the test section is close to ambient conditions which is verified by monitoring the temperature and pressure readings at positions 1, 2, and 11 according to Fig. 1a. The variation of air and liquid temperatures was verified to be in the range of $\pm 3{ }^{\circ} \mathrm{C}$ and the pressure within $+30 \mathrm{kPa}$ around ambient conditions.

\subsection{Test section}

For the present work, two different test sections have been investigated according to Fig. 1c and d:

- case A: straight pipe with $223 D$ total length

- case B: equal-diameter pipe with a total length of $196 D$ and a circular orifice (area ratio $\sigma=0.6$, thickness
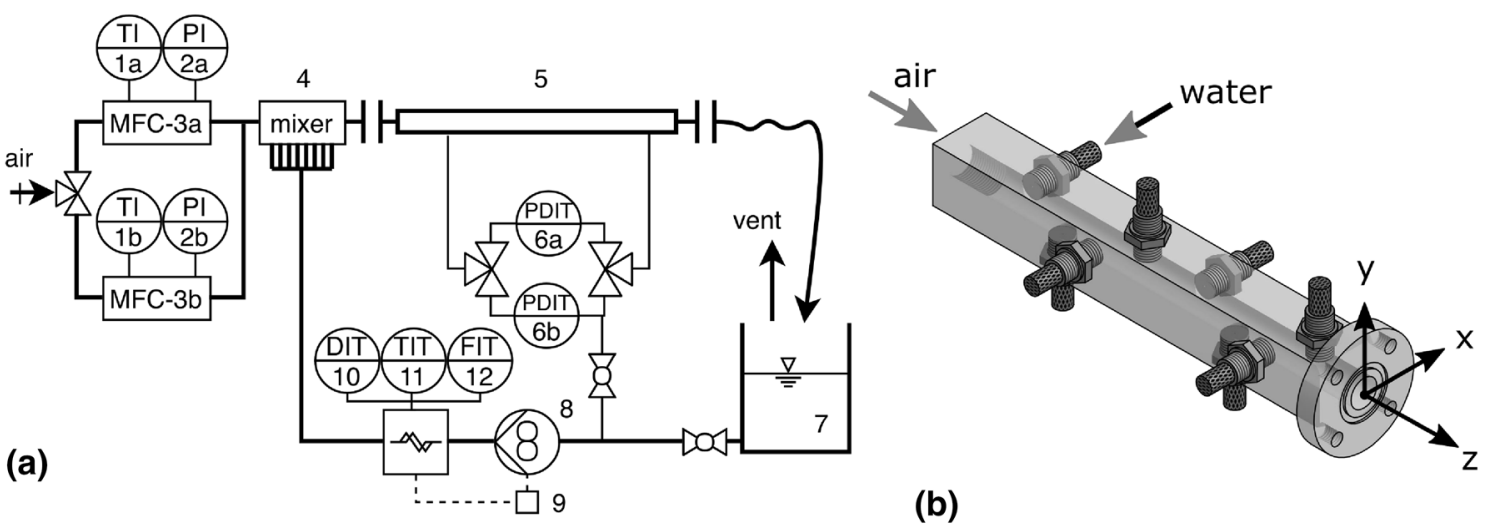

(b)

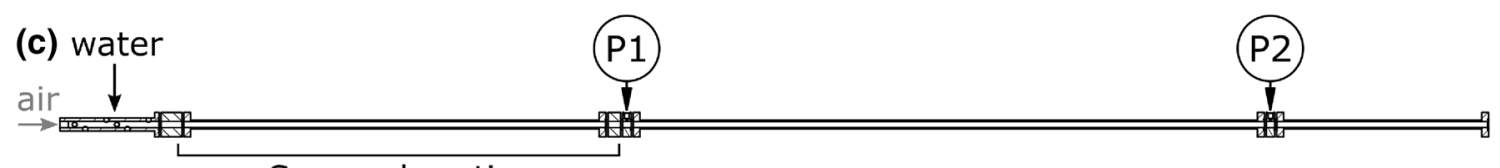

Scanned section

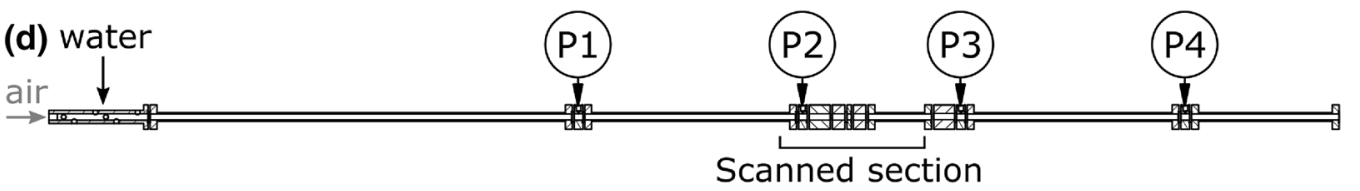

Fig. 1 a Schematic of air-water flow loop: 1-3-mass flow controller, 4-mixing section, 5-test section, 6-differential pressure transducers, 7-tank, 8-geared pump, 10-12-water mass flow meter, 9-pump frequency inverter; $\mathbf{b}$ drawing of mixing section with spray nozzles and coordinate system; $\mathbf{c}$ test section for case A; $\mathbf{d}$ test section for case B (not to scale) 
$0.07 \mathrm{D}$ ) positioned $116.4 \mathrm{D}$ downstream of the mixer outlet.

Each test section is composed of flanged transparent PMMA pipe modules to enable optical observations and to reduce $\mathrm{X}$-ray attenuation in the pipe wall. The z-direction of the Cartesian measurement coordinate system $(x, y, z)$ is aligned with the horizontal pipe axis according to Fig. $1 \mathrm{~b}$ with gravity acting in $-y$ direction. For convenience, a cylindrical coordinate system $(r, \varphi, z)$ is defined such that $x=r \sin (\varphi)$, $y=r \cos (\varphi)$ and $z=z$. The following normalized coordinates are introduced:

$\left(x^{\prime}, y^{\prime}, z^{\prime}\right)^{\mathrm{T}}=1 / D(x, y, z)^{\mathrm{T}}$

$\left(r^{\prime}, \varphi^{\prime}, z^{\prime}\right)^{\mathrm{T}}=(2 r / D, \varphi / \mathrm{rad}, z / D)^{\mathrm{T}}$.

The pipe sections which are scanned with the $\mu \mathrm{CT}$ system are indicated in Fig. 1c and d. For case A the pressure drop is measured in a $107 \mathrm{D}$ long pipe section between $\mathrm{P} 1$ and $\mathrm{P} 2$. The exact tap positions are stated in Table 1.

\section{X-ray microtomography system}

\subsection{Setup}

A microfocus X-ray computed tomography (CT) system was installed around the horizontal air-water flow loop as shown in Fig. 2 to non-invasively measure the three-dimensional liquid volume fraction distribution along the test section.

The CT system is mounted on a mobile support frame and comprises a microfocus X-ray tube (XrayWORX XWT - 190 - TC) and a two-dimensional flat panel X-ray image detector (PerkinElmer XRD 0822 AP3 IND; $205 \times 205$ mm $^{2}$ total active area covered by $1024 \times 1024$ pixels). The X-ray tube and the detector are attached to a motorized rotary stage (Aerotech AGR150) with the flow loop being fed through the rotary stage's horizontally aligned hollow shaft. The distance between the rotational axis and the X-ray tube and detector were chosen so that high magnification factor was achieved while collision with the experimental assembly was prevented. Thus, the size of the visualised volume in axial direction is 5.7 D. During a tomographic scan the rotary stage continuously drove the source-detector assembly around the test section over an angular range of $360^{\circ}$ at

Table 1 Location of pressure taps downstream of inlet

\begin{tabular}{lllll}
\hline case & $z_{\mathrm{P} 1} / D$ & $z_{\mathrm{P} 2} / D$ & $z_{\mathrm{P} 3} / D$ & $z_{\mathrm{P} 4} / D$ \\
\hline A & 77.9 & 186.4 & & \\
$\mathrm{~B}$ & 72.1 & 109.3 & 133.6 & 170.7 \\
\hline
\end{tabular}

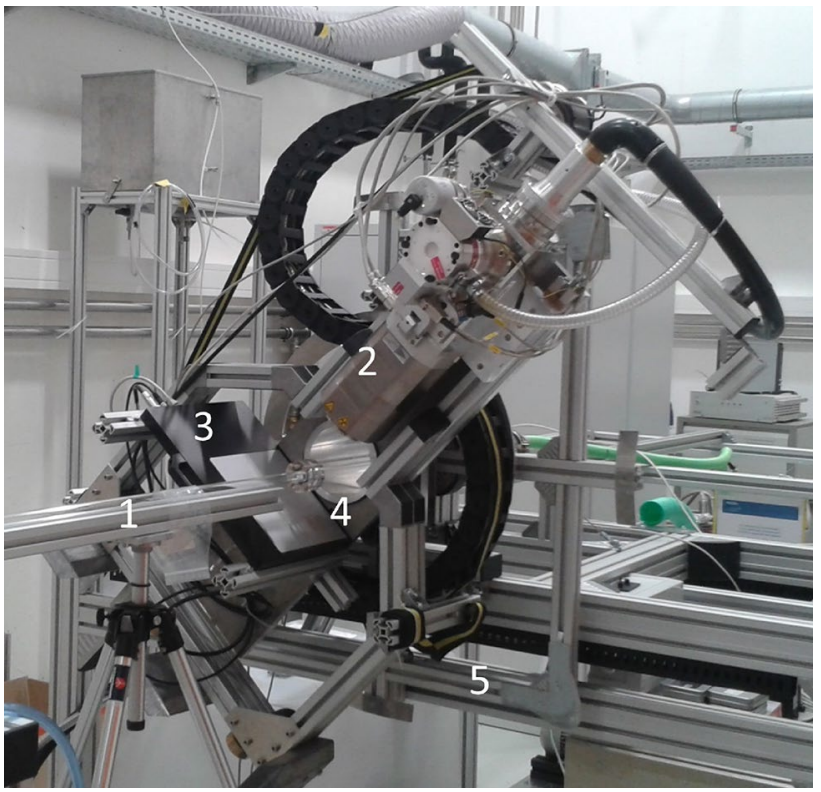

Fig. 2 Microfocus X-ray computed tomography system, 1-test section, 2-microfocus X-ray source, 3-flatpanel X-ray detector, 4rotary unit, 5-mobile support platform

a speed of $0.3 \%$, resulting in a duration of a single scan of twenty minutes. The $\mathrm{X}$-ray source was continuously operated at a tube voltage of $140 \mathrm{kV}$ and a tube current of 70 $\mu \mathrm{A}$. At the same time the $\mathrm{X}$-ray detector was continuously read out with an integration time of $600 \mathrm{~ms}$ which resulted in 2000 projection images during a full rotation. The measurement procedure is shown schematically in Fig. 3. Once a tomographic scan was finished the rotary stage needed to be rotated back to its start position. To cover longer pipe sections, the mobile CT system was manually shifted in the direction of the pipe's axis before each subsequent CT scan.

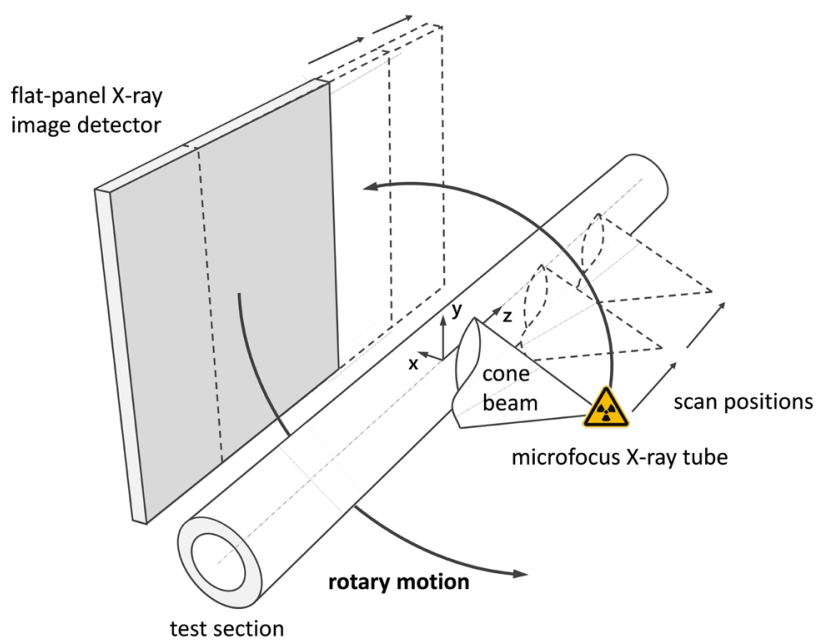

Fig. 3 Schematic drawing of the measurement procedure 
To achieve axial precision, the CT system was moved along a guiding rail and positioned at corresponding markers.

\subsection{Image reconstruction and analysis}

Raw projection image pre-processing includes dark field subtraction to compensate for the detector's dark current, and multiplicative correction of the individual pixel gain deviations using a bright field image. Defective pixel values are replaced by average values of non-defective neighboring pixels. Fluctuations in the X-ray beam intensity are compensated offline by application of frame-wise multiplicative correction factors which are determined from X-ray beams close to but not penetrating the test section. Furthermore, the images are corrected for rotation and tilt of the detector and are centered with subpixel accuracy using linear image interpolation considering the projection geometry of each beam between source and each detector pixel. The rotation and tilt angles are determined using a reference phantom measurement and are $0.24^{\circ}$ and $0.00^{\circ}$, respectively, for the experiments presented here.

Three-dimensional image reconstruction from the preprocessed projection data was achieved using an own GPUbased implementation of the Feldkamp-Davis-Kress algorithm, which essentially is a filtered backprojection (FBP) (Feldkamp et al. 1984; Kak and Slaney 1987). The FDK algorithm is a generalization of the 2D fan beam FBP into $3 \mathrm{D}$ for cone beam projection data acquired from a circular orbit. In case of horizontal axis of rotation a column-wise filtering of weighted 2D projection data is required to equalize the response of the back-projection step in the spatial frequency domain. As a result, the three-dimensional spatial distribution of the time-averaged effective X-ray attenuation $\mu_{\text {eff }}(x, y, z)$ of the test section and fluids flowing therein is obtained, cf. Fig. 4 upper row.
With the knowledge of the local effective X-ray attenuation of the gas, $\mu_{\mathrm{G}}(x, y, z)$, and of the liquid, $\mu_{\mathrm{L}}(x, y, z)$-from corresponding reference measurements with the test section either completely air-filled or water-filled - the local liquid fraction $\alpha_{\mathrm{L}}(x, y, z)$ can be computed,

$\alpha_{\mathrm{L}}=\frac{\mu_{\mathrm{eff}}-\mu_{\mathrm{G}}}{\mu_{\mathrm{L}}-\mu_{\mathrm{G}}}=\frac{\mu_{\mathrm{eff}}-\mu_{\mathrm{G}}}{\mu_{\mathrm{ref}}}$.

To enable such a calculation, precise alignment of the three datasets $\mu_{\mathrm{eff}}, \mu_{\mathrm{G}}$ and $\mu_{\mathrm{L}}$ is required. Therefore, the outer and inner surfaces of the test section and their axial offsets are extracted from each of the three-dimensional datasets. Subsequently they are resampled so that the test section's axes precisely coincide. Performing a multi-point calibration for $\alpha_{\mathrm{L}}$ is impractical as intermediate fluid densities between that of air and water at ambient conditions cannot be set with the current experimental setup.

However, blur is notable in the images at the edges of the test section. This blur invalidates Eq. (1) at the edge of the inner cross section of the pipe. Therefore, the local reference attenuation $\mu_{\text {ref }}$ has been extrapolated in radial direction beyond the pipe's inner radius to obtain a modified reference attenuation $\mu_{\mathrm{ref}}^{*}$ which is assumed to be valid even outside the pipe's inner cross section, cf. Fig. 5. Subsequently, the liquid volume fraction was computed according to

$\alpha_{\mathrm{L}}^{*}=\frac{\mu_{\mathrm{eff}}-\mu_{\mathrm{G}}}{\mu_{\mathrm{ref}}^{*}}$.

Exemplary images of the liquid volume fraction computed according to Eq. (2) at different flow regimes are shown in the lower row of Fig. 4. In the first case the pipe was completely filled with water (the liquid-only reference measurement). When computing local liquid volume fraction, the pipe cancels completely out and only the liquid
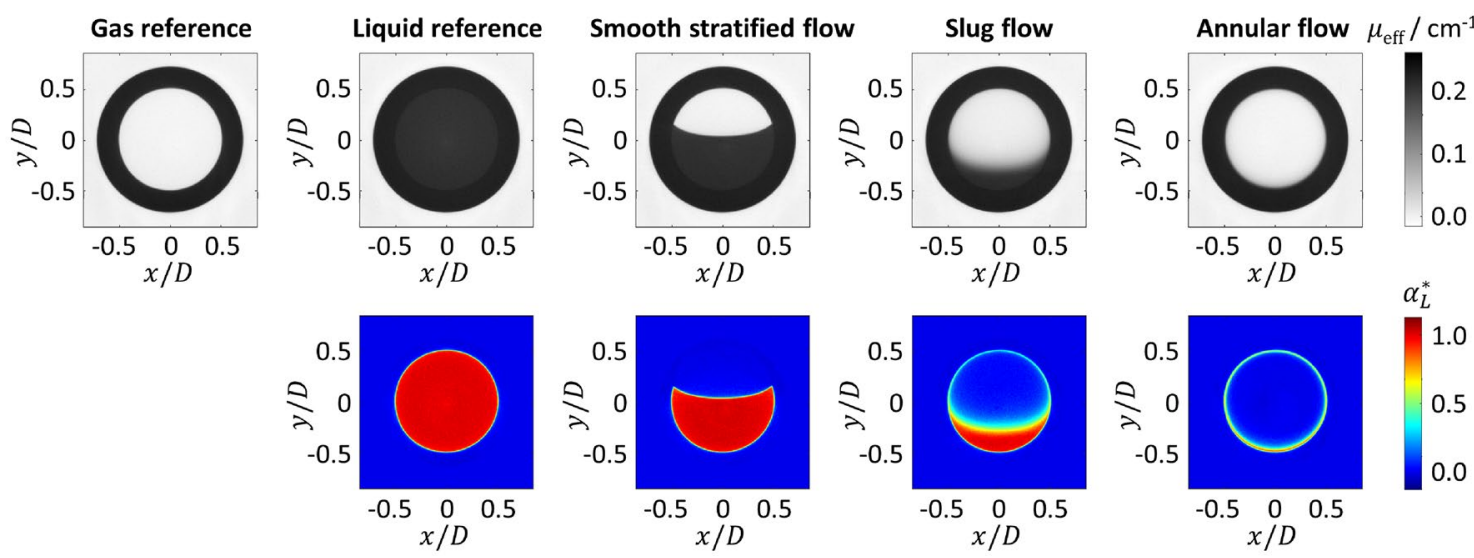

Fig. 4 Exemplary reconstructed X-ray attenuation $\mu_{\text {eff }}$ (upper row) and corresponding local liquid fraction $\alpha_{\mathrm{L}}^{*}$ (lower row) 


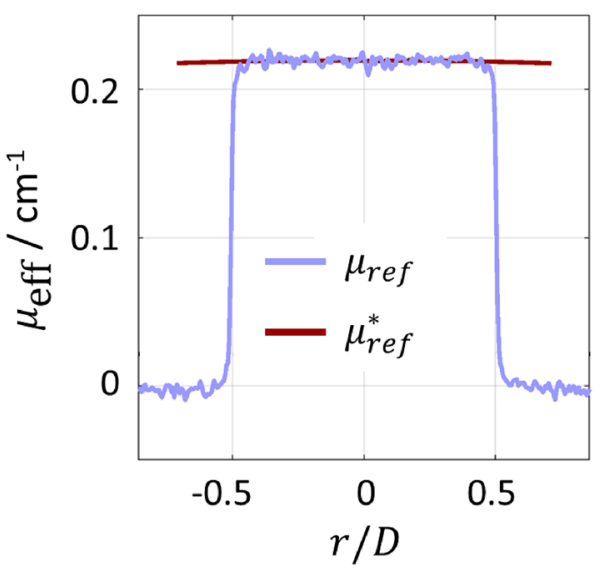

Fig. 5 Exemplary radial extrapolation of the reference attenuation $\mu_{\text {ref }}$ beyond the pipe's inner radius to obtain a valid reference $\mu_{\mathrm{ref}}^{*}$

remains in the image, whereas each liquid voxel on average shows a local liquid volume fraction of one. Thus, for the gas-only reference measurement $\alpha_{\mathrm{L}}^{*}=0$ by definition. If a smooth stratified flow develops in the pipe, voxels located in the bottom region show a liquid volume fraction of one and voxels located in the upper region show a liquid volume fraction of zero. It is pointed out that the interface between the gas and the pipe wall completely disappears in these difference images. Further, the interface between the gas and the liquid is obtained as a sharp step from one phase to the other. However, in the case of slug flow, there is no stationary interface between the phases. Instead, the flow is highly fluctuating forming large-amplitude waves and droplets stripping from the wave crest. Due to the fact, that the CT system can only perform time averaged measurements, these effects are represented by an interface transition zone between the liquid film and the gas core in the images. Further, in case of slug and annular flow, a liquid film covers the inner pipe wall, which easily can be identified in the corresponding CT images. If the film thickness, on average, is smaller than the spatial resolution of the CT system, the maximum observed local liquid fraction in the film is less than one.

Another disadvantage of Eq. (1) is the fact, that the equation divisor $\mu_{\text {ref }}$ becomes zero outside of the pipe's inner cross section. That would require precise masking of the results with the risk to miss or to truncate a liquid film close to the pipe's wall. This problem is inherently overcome by application of the modified reference attenuation $\mu_{\mathrm{ref}}^{*}$ in Eq. (2) which is assumed to be valid even beyond the pipe's inner cross section. Then, the integral liquid fraction $\overline{\alpha_{\mathrm{L}}^{*}}(z)$ across the pipe's inner cross section simply can be computed by integration

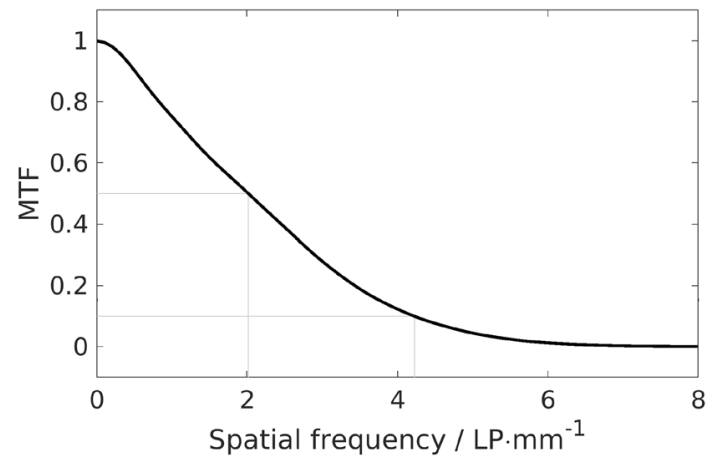

Fig. 6 Average modulation transfer function of the microfocus X-ray CT setup

$\overline{\alpha_{\mathrm{L}}^{*}}(z)=\frac{1}{A(z)} \int_{\varphi=0}^{2 \pi} \int_{r=0}^{R^{*}} \alpha_{\mathrm{L}}^{*}(r, \varphi, z) r \mathrm{~d} r \mathrm{~d} \varphi$,

with $R^{*}=R+\Delta R$ being the pipe radius extended by the width of the spatial blur. In (3), $A \approx \pi R^{2}$ denotes the pipe's cross-sectional area, which precisely can be measured by integration of the liquid volume fraction in the full reference data,

$A(z)=\int_{\varphi=0}^{2 \pi} \int_{r=0}^{R^{*}} \alpha_{\mathrm{L}, \mathrm{full}}^{*}(r, \varphi, z) r \mathrm{~d} r \mathrm{~d} \varphi$.

\subsection{Uncertainty analysis}

Spatial resolution: If the transfer function of the imaging system is non-ideal, then the resulting images get blurred. In case of X-ray CT this is caused by the finite size of the detector's pixels and the X-ray tube's focal spot size, and further by mechanical tolerances of the rotating stage. The imaging performance of the current setup was assessed by considering the reconstructed image of a density jump at the inner wall of an air-filled test section. In analogy to optical systems, the modulation transfer function (MTF), i.e. the Fourier transform of the edge spread function across the pipe wall, is computed to find the maximum spatial resolution of the setup, see Fig. 6. It was found that an average spatial resolution of $2.0 \mathrm{LP} / \mathrm{mm}$ (line pairs per $\mathrm{mm}$ ) was achieved at MTF $=0.5$. Further, each dataset was tested and it was found that pipe vibrations caused by pulsating flows were sufficiently small and did not affect the observed spatial resolution.

Statistical noise: The accuracy of the measured local liquid volume fraction $\alpha_{\mathrm{L}}(x, y, z)$ is reduced by noise and image artifacts. Image noise is a result of the Poisson distributed photon noise of the X-ray source, of the attenuation in the test section and of the electronic noise in the detector 
module. The resulting stochastical uncertainty in the local liquid fraction was measured by computing the standard deviation of volume fraction values in all voxels within the pipe's inner cross section for the full reference dataset, and the uncertainty was found to be less than $1.5 \%$ absolute liquid fraction per voxel. The noise is larger for measurements in the flanges of the test section's modules, since more X-ray photons get attenuated. However, there the image noise is still less than 3\% absolute liquid fraction per voxel at those positions.

Spectral effects: Beam hardening and scattered radiation cause nonlinearities in the quantitative transfer function of the X-ray imaging system, i.e. observed attenuation values become smaller in the center than in outer regions of a test object for the same material. If the magnitude of such effects depends on the amount of liquid in the test section, then errors might occur in the liquid volume fraction measurements. Attenuation profiles through the air-filled and liquidfilled test section have been extracted and were compared, and it was determined that these nonlinearities might cause an uncertainty in the center of the pipe of at maximum 5\% relative of the local liquid fraction.

Resampling: For the computation of local liquid volume fraction difference images have to be computed. Due to the weight difference of the test section for air-only, water-only and two-phase measurements, minor mechanical displacements could not be prevented here. Thus, a resampling of the reconstructed attenuation values was required. This leads to the fact that voxels from different spatial positions in the beam geometry with different energy spectra are compared, which results in the appearance of image artifacts. This is demonstrated in Fig. 7. The reconstructed attenuation in
Fig. 7a shows image artifacts which are related to spatial variant nonlinearities of the imaging system, e.g. the intensity for each beam in artifact B varies non-uniformly along the projection angle. These spatial variations did not cancel out in difference images after resampling and therefore cause artifacts in local and integral liquid volume fraction which are shown in Fig. 7b and c, respectively. This unexpected spatial variation of the $\mathrm{X}$-ray systems transfer function is most likely caused by a focus shift of the electron beam during rotation of the microfocus X-ray source. Although these artifacts are systematic, no way was found to correct for them. The magnitude of these errors has been estimated to be $\pm 5 \%$ integral liquid fraction.

To avoid resampling in axial direction, the experimental procedure could be changed in principle, so that full, empty and two-phase measurements are taken before repositioning the CT system. However, emptying and flooding the test section is elaborate, since all droplets or bubbles, respectively, have to be removed. Within this study, this error prone and time-consuming process, which would have to be repeated at each measurement position nonetheless, was avoided.

Dynamic bias: Although the annular flow under investigation is a fully developed flow, it nevertheless has a fluctuating film due to ripple and disturbance waves so that the liquid fraction averaged along the beam path is temporally varying $\left\langle\alpha_{\mathrm{L}}\right\rangle=f(t)$. It is known then that the quantification of volume fraction using radiation methods is prone to dynamic bias error due to the exponential form of the attenuation law (Hampel and Wagner 2011; Wagner et al. 2016)
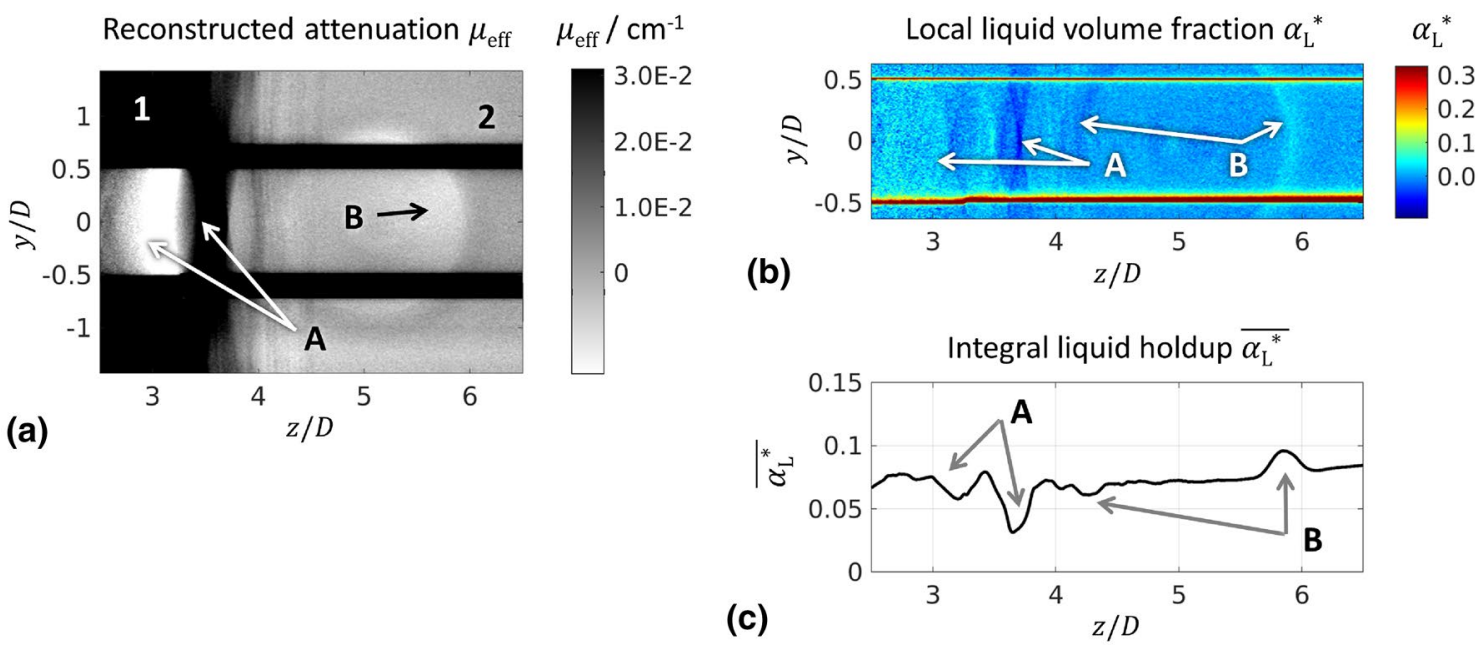

Fig. 7 Demonstration of the effect of spatially variant nonlinearities of the imaging system (a) on the local and integral liquid volume fraction in case of annular flow $(\mathbf{b}, \mathbf{c}), 1$ - flange, 2-pipe, A-artifacts due to scattered radiation, B-artifacts due to beam inhomogenities 


$$
\begin{aligned}
\Delta\left\langle\alpha_{\mathrm{L}}\right\rangle= & -\frac{1}{\lambda} \ln \left[\frac{1}{\tau} \int_{0}^{\tau} e^{-\lambda\left\langle\alpha_{\mathrm{L}}(t)\right\rangle} \mathrm{d} t\right] \\
& -\frac{1}{\tau} \int_{0}^{\tau}\left\langle\alpha_{\mathrm{L}}(t)\right\rangle \mathrm{d} t,
\end{aligned}
$$

where $\lambda$ is the free-mean-path length through the pipe of the transmitting radiation and $\tau$ is the time interval of measurement. To assess the effect of dynamic bias in tomographic measurement of integral holdup in annular flow with varying liquid film thickness (LFT), a set of synthetic, symmetric annular flow images was generated, forward projected, reconstructed and analyzed. The LFT was assumed to be lognormal distributed, as exemplary shown in Fig. 8a, with $\delta_{0}$ being the LFT at the maximum of the distributions probability density function (PDF). The matrix of all cases tested is given in Fig. 8b. A linear attenuation coefficient of $\mu_{\mathrm{L}}=0.22 \mathrm{~cm}^{-1}$ was used. Theoretically, a maximum absolute error in measured integral integral liquid fraction of $2.5 \%$ for a standard deviation of $30 \%$ is possible. Practically, for the range of film thicknesses investigated, the error is below $1.5 \%$.

\subsection{Liquid film thickness calculation}

To calculate the liquid film thickness from the reconstructed liquid volume fraction distribution $\alpha_{\mathrm{L}}^{*}(r, \varphi, z)$ we adopt the approach by (Zboray 2011). This model based method assumes a wall-bounded film with randomly fluctuating height $h$. In this case, the liquid volume fraction is related to the probability density function (PDF) of the film height

$f_{h}(y)=-\frac{\mathrm{d} \alpha_{\mathrm{L}}}{\mathrm{d} y}$,

where $y=R-r$ is the wall normal distance. With that, the normalized mean film thickness $H$ is calculated as the expected value of the PDF

$$
\begin{aligned}
H^{\prime}(\varphi, z) & =\frac{2}{D} \int_{0}^{\infty} y f_{h}(y) d y \\
& =\frac{2}{D} \int_{y_{\text {min }}}^{y_{\text {max }}} \alpha_{\mathrm{L}}^{*}(R-y, \varphi, z) \mathrm{d} y .
\end{aligned}
$$

The integration limits $y_{\min }, y_{\max }$ are determined from the radial liquid fraction profiles (Fig. 9) as the distance from the inner pipe wall where $\alpha_{\mathrm{L}}^{*}$ first hits the average liquid fraction in an appropriate region in the gas core and the pipe wall, respectively. Since the selection of the averaging regions is somewhat arbitrary, the sensitivity of the liquid film thickness to the variation of the integration limits was investigated. The change in the circumferential average $1 / n \sum_{j}^{n} H^{\prime}\left(\varphi_{j}, z\right)$ is typically less than $\pm 5 \%$ when increasing (decreasing) the upper (lower) integration limit by a factor of $1.3(0.7)$. Other factors have been tested and they show the same trend. In case $\mathrm{B}$, the sensitivity of the averaged $H^{\prime}$ can exceed $+10 \%$ in an axial range of $2.5 \mathrm{D}$ downstream of the orifice due to the larger entrained liquid fraction in the

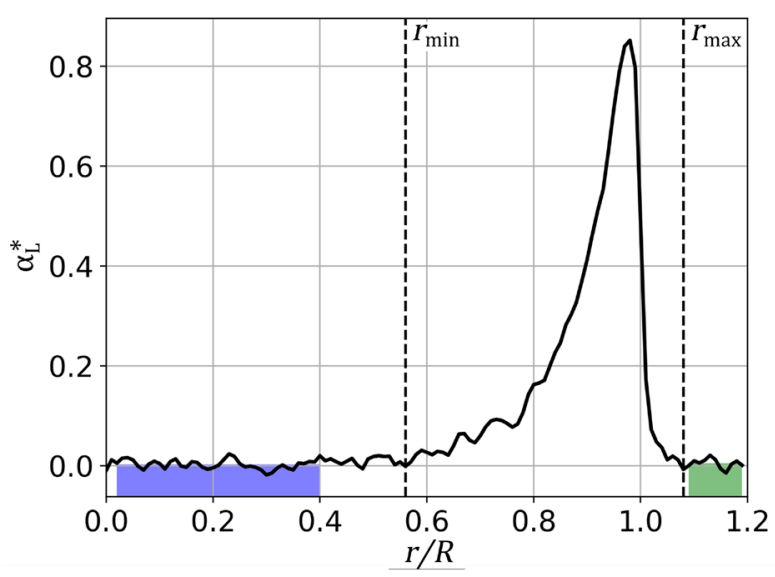

Fig. 9 Exemplary radial liquid volume fraction profile for case A with integration limits for Eq. (7), averaged liquid volume fraction in core region (blue) and wall region (green) indicated

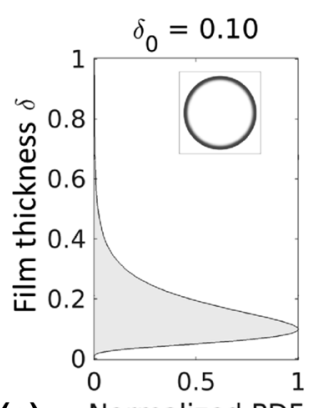

(a)

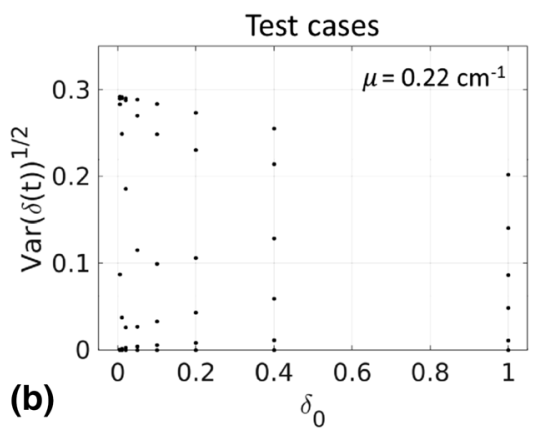

(b)
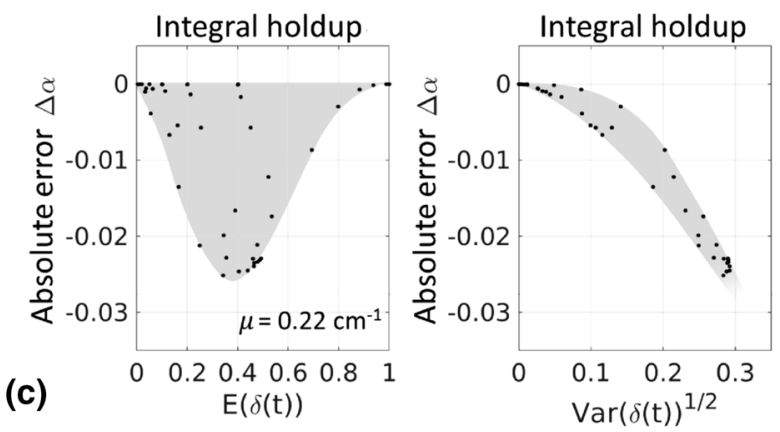

Fig. 8 Assessment of the dynamic bias in tomographic measurement of integral holdup in annular flow with varying liquid film thickness using synthetic flow images, a exemplary PDF of liquid film thick- ness with corresponding cross sectional view, $\mathbf{b}$ matrix of test cases, $\mathbf{c}$ resulting dynamic bias 
gas core. Outside of this axial range, the mean liquid fraction was considered to be insensitive to variations of the integration limits.

The axial averaged liquid film thickness $\overline{H^{\prime}(\varphi)}$ is calculated analogously to Eq. (7) from the axially averaged liquid volume fraction $\overline{\alpha^{*}(\varphi)}$. The root mean square deviation from $\overline{H^{\prime}\left(\varphi_{j}\right)}$ along angular positions $j$ is then defined as

$H_{\mathrm{rms}}^{\prime}=\left\{\frac{1}{n_{\varphi}} \sum_{j=1}^{n_{\varphi}}\left(H^{\prime}\left(\varphi_{j}, z\right)-\overline{H^{\prime}\left(\varphi_{j}\right)}\right)^{2}\right\}^{\frac{1}{2}}$,

to quantify the development length of the film thickness profile in Sect. 5.

\section{Experimental procedure}

A flow regime map was initially created for the horizontal straight pipe (case A) by observing the flow at a position $z / D=72.5$ downstream of the inlet with a High-Speed Camera. The resulting map compared favourably with the wellknown flow map of Taitel and Dukler (1976), exemplary flow visualisations in four different regimes are shown in Fig. 10. The flow regimes were subsequently set by varying the gas and liquid flow rates according to this flow map. For the experiments reported in this paper, annular flow conditions are set with constant air and water flow rates corresponding to $R e_{\mathrm{G}}=25000$ and $R e_{\mathrm{L}}=4090$, respectively. Here, $R e$ denotes the Reynolds number based on the superficial velocity. These flow conditions correspond to a Martinelli parameter of 0.4 and to point 4 in Fig. 10.
Table 2 Differential pressure measured for case A compared to different pressure drop correlations

\section{Experiment}

$7323 \mathrm{~Pa} / \mathrm{m}$

Schubring et al. (2008)

$7284 \mathrm{~Pa} / \mathrm{m}$

Friedel (1979)

Lockhart and Martinelli (1949)

$8650 \mathrm{~Pa} / \mathrm{m}$

$6949 \mathrm{~Pa} / \mathrm{m}$

Additionally, the linear pressure drop measured in case A was checked to favourably compare to established pressure drop correlations for annular flow to verify that fully developed annular flow is obtained, cf. Table 2. With steady-state mass flow rates, temperatures and pressure drop reached, the CT measurements were performed in a sequential manner. After each measurement the CT system was traversed along the pipe axis so that a total pipe length of $3 \leq z / D \leq 78$ was scanned in case A and $109 \leq z / D \leq 133$ in case B.

\section{Results and discussion}

\subsection{Volume fraction development}

The integral liquid volume fraction (LVF) according to (3) along the pipe axis is shown in Fig. 11.

Note that the plot shows stacked results from multiple CT scans, whose boundaries are indicated by solid grey lines. Systematic overshoots and undershoots are evident around the center of each scan position. These deviations are a consequence of the resampling bias described in Sect. 3.3 and cannot be avoided with the current experimental setup. In
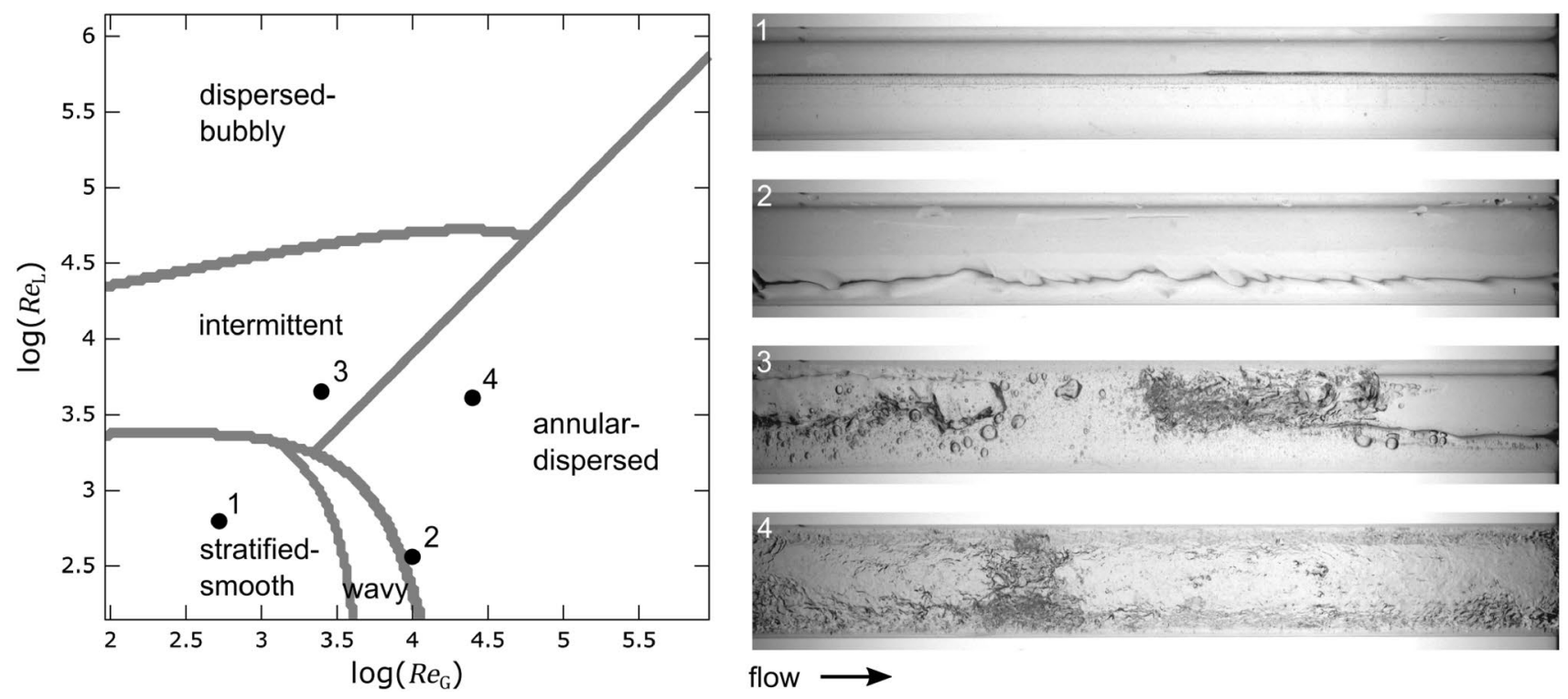

Fig. 10 High-speed visualisation of air-water flow in pipe test section (case A) and corresponding operating points in Taitel-Dukler flow map 

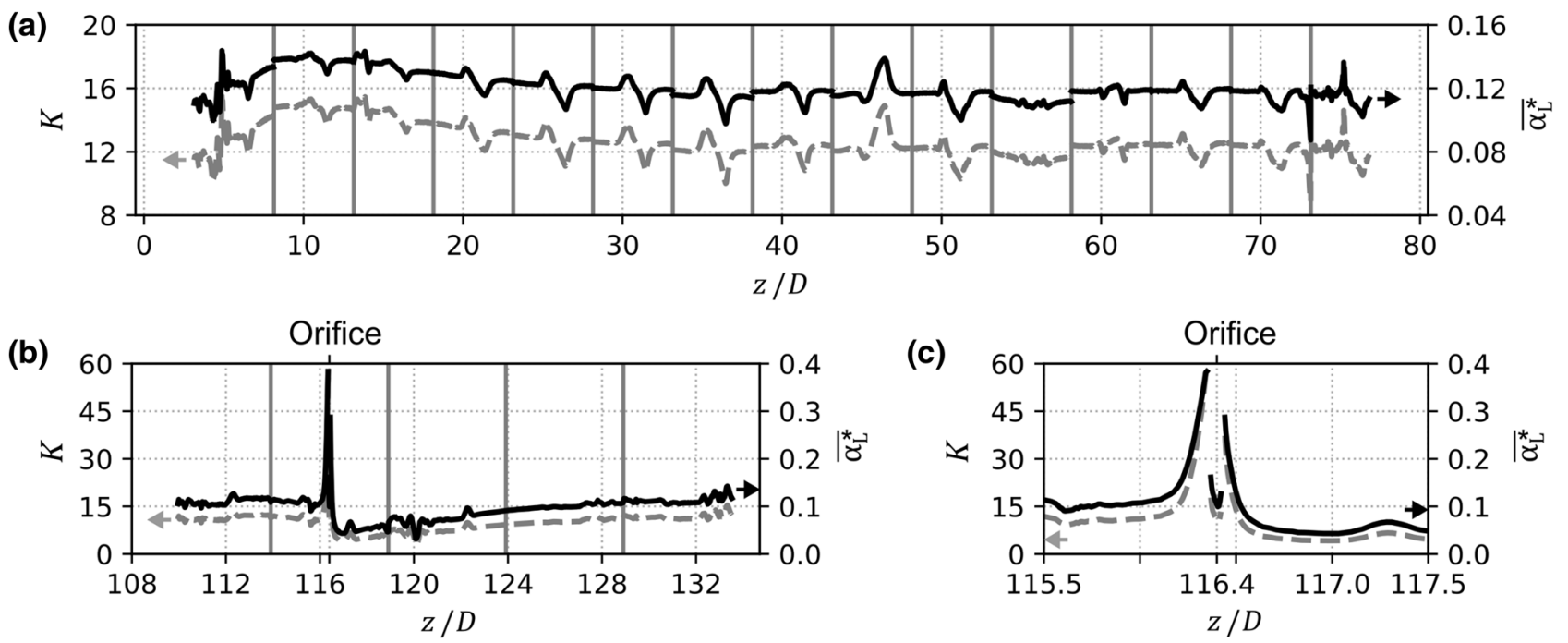

Fig. 11 Cross-sectional averaged liquid volume fraction and phase slip ratio, a case A, b case B, c detail view of case B, $\overline{\alpha_{\mathrm{L}}^{*}}$ drawn as solid line, $K$ drawn as dashed line, solid grey lines indicate boundaries between CT scans

Fig. 11a, starting from the mixer outlet at $z / D=0$, the LVF along the straight pipe initially increases before reaching a constant level of $\overline{\alpha_{\mathrm{L}}^{*}}=0.12$. This development is expected since the liquid droplets are initially injected radially into the gas stream with negligible axial velocity. Consequently, the phase slip ratio expressed by the bulk velocities $K=U_{\mathrm{G}} / U_{\mathrm{L}}$ at the mixer outlet is initially increased according to phase continuity

$K=\frac{\rho_{\mathrm{L}}}{\rho_{\mathrm{G}}} \frac{\dot{x}}{1-\dot{x}} \frac{\alpha_{\mathrm{L}}}{1-\alpha_{\mathrm{L}}}$,

where $\dot{x}=\dot{M}_{\mathrm{G}} /\left(\dot{M}_{\mathrm{G}}+\dot{M}_{\mathrm{L}}\right)$ is the dryness fraction. The velocity ratio decreases further downstream, it follows from Fig. 11a that the fully developed state, i.e. constant LVF and $\mathrm{K}$, is reached at $z / D>30$ in case $\mathrm{A}$.

The circular orifice in case B is positioned well within the region of developed annular flow at $z / D=116.4$, so that the LVF upstream of the orifice in Fig. 11b is comparable to case A. The influence of the orifice on the upstream volume fraction is limited to an axial distance of less than one pipe diameter. This is in accordance with previous measurements by McQuillan and Whalley (1984) who found no upstream effect at $L / D \approx-1$ in case of vertical annular flow. Closer to the orifice, a liquid pool is retained with a maximum LVF of 0.38 which compares well to the area fraction of 0.4 blocked by the orifice. To a lesser extent, liquid pooling is also observed in the near-orifice recirculation region on the downstream side of the orifice where the maximum LVF reaches 0.29 . As the flow accelerates through the orifice, the phase slip initially increases due to the larger inertia of the liquid phase which is evident from the $\mathrm{K}$ profile. Consequently, increased gas-liquid interfacial shear causes stripping of liquid droplets from the liquid pool at the orifice which subsequently are accelerated by the gas stream. The droplet stripping is reflected in reduced LVF and $\mathrm{K}$ in the wake region of the orifice. These findings are questioning the earlier results by Salcudean et al. (1983) who described a decreased void fraction effect due to the orifice and are more in line with the findings by Sekoguchi (1978) and McQuillan and Whalley (1984). The latter showed that the minimum film thickness and film flow rate decrease on the downstream side of the orifice which was attributed to enhanced droplet entrainment. Their findings also imply an increased void fraction effect.

The wake region in Fig. 11b stretches from the orifice position to $z / D=130$, corresponding to a development length $L / D=13.6$ of the LVF. As the flow recovers from the disturbance, the LVF converges to the a constant value of 0.12 which signifies that fully developed annular flow is reestablished.

Additionally, the total liquid hold-up in the pipe was integrated from the LVF data. In case B the total hold-up is 0.0956 in the scanned section of $25 \mathrm{D}$ length, whereas in case A a hold-up of 0.115 is obtained in a section of equal length $48.1<z / D<73.1$. Clearly, the liquid entrainment in the gas-core is enhanced by installing the circular orifice, so that the liquid hold-up is reduced.

The CT measurements enable a more detailed view on the time-averaged flow structure through the orifice. A threedimensional rendering of the liquid volume fraction distribution $\alpha_{\mathrm{L}}^{*}(r, \varphi, z)$ of case B is given in Fig. 12, where the liquid fraction range below $5 \%$ is made transparent.

Upstream of the orifice most of the liquid phase is attached to the pipe wall and forms a liquid film with 


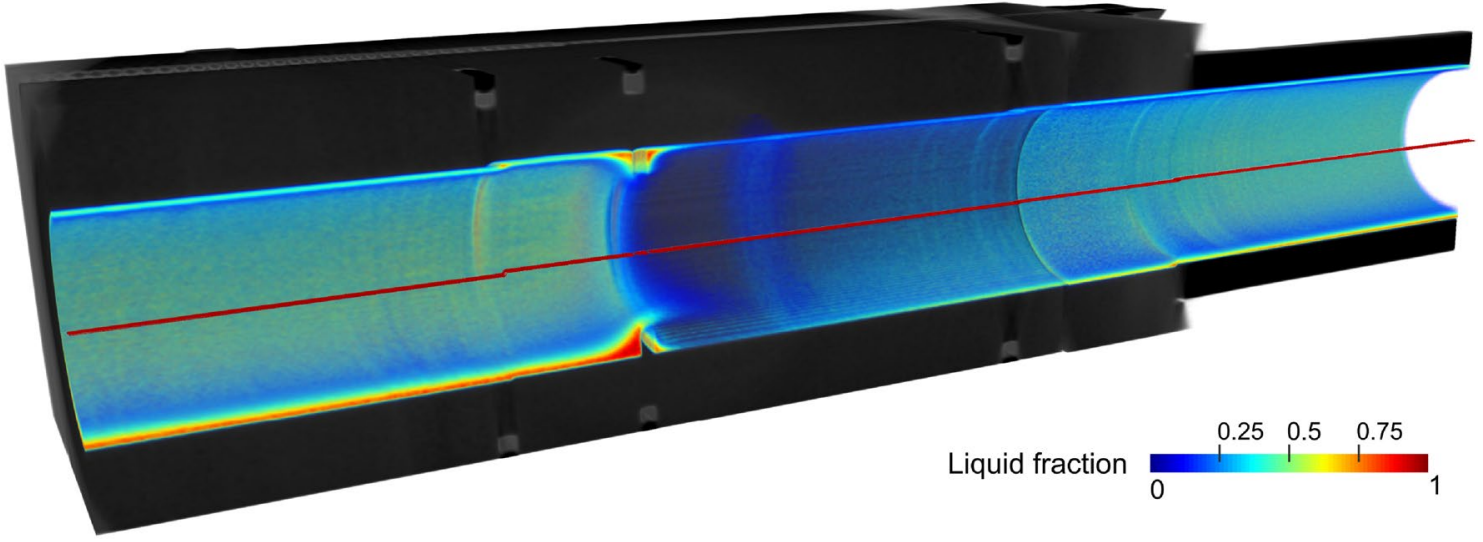

Fig. 12 Visualisation of the reconstructed liquid fraction distribution in annular flow through circular orifice (case B) for $113.9<z / D<121.4$, fitted pipe axis given as red line

varying thickness. Due to gravity a characteristic liquid volume fraction profile for horizontal annular flow is observed where the liquid phase accumulates at the pipe bottom. The liquid film in annular flow is known to develop small amplitude ripple waves and large amplitude disturbance waves (Alekseenko 2014). These film thickness fluctuations are reflected by smooth transition zone $0<\overline{\alpha_{\mathrm{L}}^{*}}<1$ in the time-averaged liquid volume fraction distribution, which is visible near the pipe bottom in Fig. 12.

While there is a clear relation between fluctuating film waves and time averaged liquid fraction, this is not the case for the liquid stripping from the orifice. An annular liquid sheet with vanishing liquid volume fraction is visible at the orifice in Fig. 12. This may be representative of either a fluctuating filament or accelerating droplets. Time resolved measurements are required here to further interpret the tomographic images.

Downstream of the orifice a sudden drop of the liquid fraction is observed globally, which originates from the liquid annulus break up into liquid droplets and the slip velocity decrease. Here, the liquid fraction at the pipe wall drops below one since the liquid film thickness is below the spatial resolution of the CT system. However, optical observations showed that the pipe wall remains wetted downstream of the orifice. As the entrained liquid droplets impinge on the liquid film, the liquid volume fraction increases downstream of the orifice. Figure 12 shows that the liquid fraction at the wall downstream of the orifice is symmetrically distributed and a developing length is required until an asymmetrical distribution is formed. This can be interpreted as a consequence of the turbulent recirculation flow which drives small diameter drops homogeneously to the pipe wall whereas large diameter droplets impinge by gravitational settling further downstream. The fully developed liquid fraction profile is reestablished outside of the rendered pipe section.
Radial offsets between axis of neighbouring test section modules are visible in Fig. 12. These could not be avoided in the test section assembly despite the special care taken to align the modules. However, the maximum offset observed is below $2 \%$ of the pipe diameter which is not seen to affect the phase distribution significantly.

\subsection{Liquid film thickness development}

The time-averaged liquid film thickness (LFT) on the pipe wall is calculated from the reconstructed liquid volume fraction distribution according to Eq. (7) and is plotted in cylindrical coordinates in Fig. 13 for case A (top) and case B (bottom).

Similarly to the LVF results, the artifacts described in Sect. 3.3 manifest themselves as periodic fluctuations in the LFT distribution. These can clearly be seen in Fig. 13a around the center of each CT scan volume. The $H^{\prime}$ profile for case A reveals that the gas-liquid mixer does not provide a homogeneous liquid film at the outlet. This is probably related to the helical nozzle arrangement (Fig. 1b). Most of the liquid at the test section inlet is shifted to the $3 / 2 \pi$ position. Measurements of the phase distribution at the test section inlet are crucial to set the correct boundary conditions in CFD validation. This is seen as an advantage of the applied measurement technique as comparable two-phase flow experiments lack this information. A typical horizontal annular-flow LFT profile develops downstream of the test section inlet in case A, which is symmetrical to the bottom peak at $\varphi=\pi$.

In case B, the LFT cannot be evaluated immediately downstream of the orifice. This range is therefore masked in Fig. 13b. Due to the droplet stripping from the orifice, a clear separation between film region and gas core region does not exist here. However, a renewed liquid film develops further downstream of the orifice, which is initially nearly 

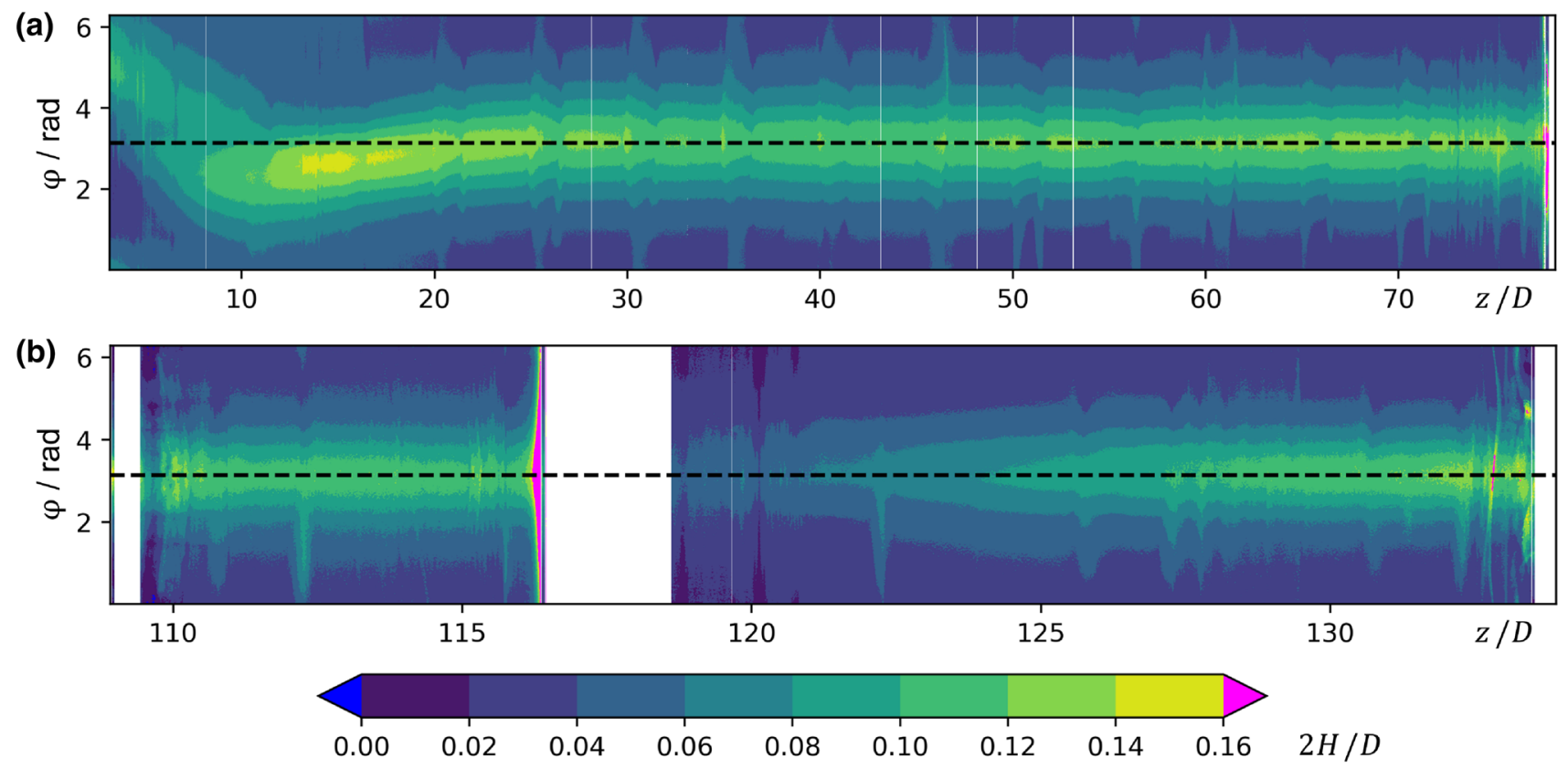

Fig. 13 Mean liquid film thickness on pipe wall (a) and on pipe wall with circular orifice positioned at $z / D=116.4$ (b), dashed line indicates pipe bottom

symmetric and develops an asymmetrical profile along the pipe axis due to gravitational action.

To quantify the development length of the LFT profiles in both cases, the root-mean square deviation $H_{\mathrm{rms}}^{\prime}$ from a fully developed profile $\overline{H^{\prime}}$ is calculated according to Eq. (8). The latter is obtained by calculating the axially averaged LFT of case A from three CT scans spanning $58.2<z / D<73.1$. $H_{\text {rms }}^{\prime}$ is plotted along the pipe axis in Fig. 14. In case A the LFT profile is considered as fully developed when a constant $H_{\mathrm{rms}}^{\prime} \leq 0.005$ is reached, which yields a development length of $25 \mathrm{D}$ from the mixer outlet. Considering case B shows convergence at $H_{\mathrm{rms}}^{\prime} \leq 0.01$ so that the LFT profile is reestablished at $z / D=130$, that is $\Delta z=13.6 \mathrm{D}$ downstream of the orifice. This agrees favorably with the development length based on the integral liquid volume fraction in Fig. 11 and with the results by (Salcudean et al. 1983) who found no downstream effect for $L / D>15$. In comparison, for the vertical case, (McQuillan and Whalley 1984) showed that the orifice influences the downstream film mass flow rate at larger axial distances of $L / D \geq 60$.

Obviously, for the given annular flow, from a converged LFT profile follows a converged LVF. However, the converse

(a)

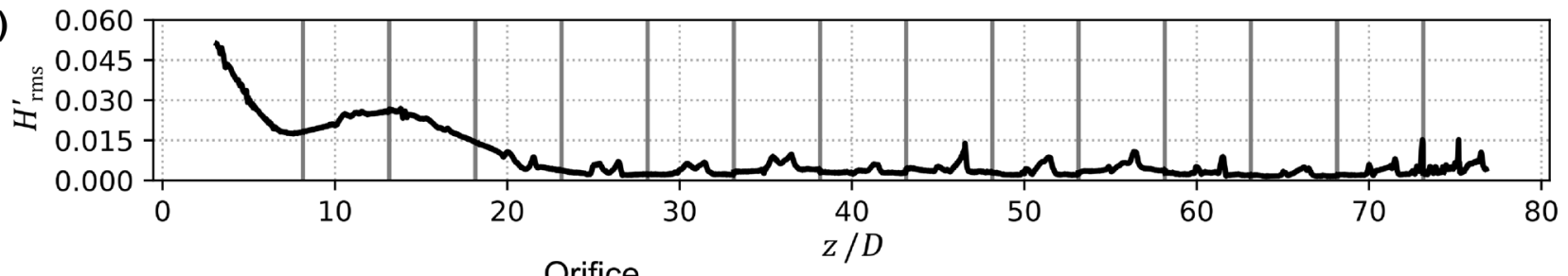

(b)

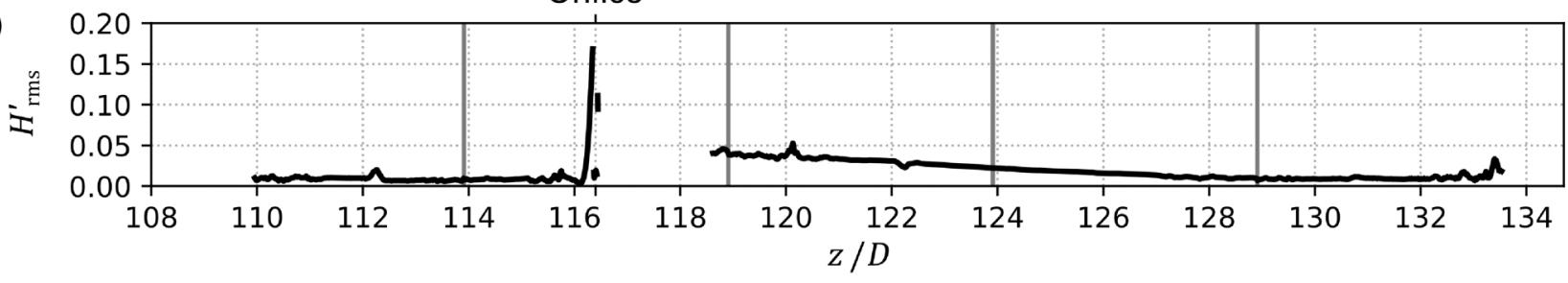

Fig. 14 Root-mean-square deviation of LFT from fully developed LFT profile along pipe axis for case A (top) and case B (bottom), solid grey lines indicate boundaries between CT scans 
argument is not generally true. Consider, for example a stratified or annular flow with stationary, meandering profile along the pipe axis. However, the agreement between LVF and $H_{\mathrm{rms}}^{\prime}$ convergence shows that - for the case of developing annular flow through an circular orifice-it is sufficient to judge the liquid film thickness development by means of the integral liquid volume fraction. The latter can also be obtained from integrating measurement techniques, such as capacitance sensors. The measured LVF distribution and LFT profiles are nevertheless valuable for the validation of multiphase CFD codes, as they allow a comparison of local quantities.

\section{Summary and conclusion}

An air-water flow loop for modular horizontal pipe test sections was set up at HZDR and tested against an established flow map, enabling the investigation of two-phase flows at ambient conditions. A mobile X-ray microtomography system was designed and applied to measure the liquid volume fraction distribution for annular flow in a straight pipe (case A) and in a pipe with a circular orifice (case B). Consequently, the liquid film thickness was evaluated from these results. The uncertainty analysis of the CT system showed that reconstruction artifacts caused by repositioning of the test section in the inhomogeneous X-ray cone beam are the dominating sources of error with an estimated maximum error magnitude of $\pm 5 \%$ liquid volume fraction.

The results revealed a meandering liquid film distribution at the test section inlet which is related to the mixing section. Measurements of the actual inlet phase distribution is a crucial factor for CFD-grade validation data. The flow development to a constant liquid volume fraction distribution was measured and a development length of $25 D$ was found. When a circular orifice with area ratio 0.6 was introduced, an increasing void fraction effect was observed on the downstream side and liquid film stripping from the orifice was visualised with the current system. Furthermore, the flow transition from dispersed flow to developed annular flow downstream of the orifice was measured, showing an initially symmetric film which converges to a bottom-peak type asymmetrical profile. The upstream effect of the orifice was limited to an axial distance of less than one diameter. Evaluating the development length for annular flow downstream of the orifice based on cross-sectional averaged liquid volume fraction and the root-mean-square deviation of the film thickness profiles yielded a comparable axial distance of 13.6 D. This indicates that film thickness development may be judged based on integral measurement techniques for the case of horizontal annular pipe flow.

Apart from this flow investigation, the high-quality tomographic data obtained can serve for validation of
CFD simulations based on phase-averaging such as the Euler-Euler method. Possible improvements of the measurement technique include ensuring constant positioning of test section within support volume while traversing to reduce reconstruction artifacts.

Funding Open Access funding enabled and organized by Projekt DEAL.

Open Access This article is licensed under a Creative Commons Attribution 4.0 International License, which permits use, sharing, adaptation, distribution and reproduction in any medium or format, as long as you give appropriate credit to the original author(s) and the source, provide a link to the Creative Commons licence, and indicate if changes were made. The images or other third party material in this article are included in the article's Creative Commons licence, unless indicated otherwise in a credit line to the material. If material is not included in the article's Creative Commons licence and your intended use is not permitted by statutory regulation or exceeds the permitted use, you will need to obtain permission directly from the copyright holder. To view a copy of this licence, visit http://creativecommons.org/licenses/by/4.0/.

\section{References}

Alekseenko SV et al (2014) Analysis of spatial and temporal evolution of disturbance waves and ripples in annular gas-liquid flow. Int J Multiph Flow 67:122-134. https://doi.org/10.1016/j.ijmul tiphaseflow.2014.07.009

Almalki N, Ahmed WH (2020) Evaluating the two-phase flow development through orifices using a synchronised multi-channel void fraction sensor. Exp Thermal Fluid Sci 118:110165. https ://doi.org/10.1016/j.expthermflusci.2020.110165

Bieberle A et al (2013) Gamma-ray computed tomography for imaging of multiphase flows. Chem Ing Tech 85(7):1002-1011

Bieberle A et al (2020) Flow morphology and heat transfer analysis during high-pressure steam condensation in an inclined tube part I: experimental investigations. Nucl Eng Des. https://doi. org/10.1016/j.nucengdes.2020.110553

Boden S, Bieberle M, Hampel U (2008) Quantitative measurement of gas hold-up distribution in a stirred chemical reactor using Xray cone-beam computed tomography. Chem Eng J 139(2):351-362. https://doi.org/10.1016/j.cej.2007.08.014

Boden S, Haghnegahdar M, Hampel U (2017) Measurement of Taylor bubble shape in square channel by microfocus X-ray computed tomography for investigation of mass transfer. Flow Meas Instrum 53:49-55. https://doi.org/10.1016/j.flowmeasin st.2016.06.004

Butterworth D (1972) Air-water annular flow in a horizontal tube. In: Proceedings of the International Symposium on Two-Phase Systems. Elsevier, pp 235-251. https://doi.org/10.1016/b9780-08-017035-0.50018-5

Cherdantsev AV et al (2019) Simultaneous application of two laserinduced fluorescence approaches for film thickness measurements in annular gas-liquid flows. Int J Multiph Flow 119:237258. https://doi.org/10.1016/j.ijmultiphaseflow.2019.07.013

Feldkamp LA, Davis LC, Kress JW (1984) Practical cone-beam algorithm. J Opt Soc Am A: 1(6):612. https://doi.org/10.1364/ josaa.1.000612

Fossa M, Guglielmini G (2002) Pressure drop and void fraction profiles during horizontal flow through thin and thick orifices. Exp 
Thermal Fluid Sci 26.5:513-523. https://doi.org/10.1016/S0894 $-1777(02) 00156-5$

Friedel L (1979) Improved friction pressure drop correlations for horizontal and vertical two phase pipe flow. 3R International $7: 485-491$

Fukano T, Ousaka A (1987) Hold-Up, frictional pressure drop and circumferential film thickness distribution of air-water twophase annular flow in horizontal and near horizontal tubes. In: Marto PJ, Tanasaw I (eds) Proceedings of the 1987 ASMEJSME Thermal Engineering Joint Conference. Vol. 5, pp 359-366

Gill LE et al (1963) Sampling probe studies of the gas core in annular two-phase flow-I the effect of length on phase and velocity distribution. Chem Eng Sci 18(8):525-535. https://doi. org/10.1016/0009-2509(63)85013-7

Govier GW, Radford BA, Dunn JSC (1957) The upwards vertical flow of air-water mixtures: I, effect of air and water rates on flow pattern, holdup and pressure drop. Can J Chem Eng 35:58

Hampel U et al (2009) Miniature conductivity wiremesh sensor for gas-liquid two-phase flow measurement. Flow Meas Instrum 20(1):15-21. https://doi.org/10.1016/j.flowmeasinst.2008.09.001

Hampel U, Wagner M (2011) A method for correct averaging in transmission radiometry. Meas Sci Technol 22(11):115701. https://doi.org/10.1088/0957-0233/22/11/115701

Heindel TJ (2011) A review of X-ray flow visualization with applications to multiphase flows. J Fluids Eng 133(7):074001. https:// doi.org/10.1115/1.4004367

Hewitt GF, Lovegrove PC, Nicholls B (1964) Film thickness measurment using a fluorescence technique: Part I, Description of the method. AERE-R- 4478. Atomic Energy Research Establishment

Hooker HH, Popper GF (1958) A Gamma-ray attenuation method for void fraction determinations in experimental boiling heat transfer test facilities. Tech. rep. ANL-5766. Argonne National Laboratory. https://doi.org/10.2172/4276982

Kak AC, Slaney M (1987) Principles of computerized tomographic imaging. Ed. by R. F. Cotellessa. New York: IEEE Press. isbn: 0-87942-198-3

Karathanassis IK et al (2018) Illustrating the effect of viscoelastic additives on cavitation and turbulence with X-ray imaging. Sci Rep. https://doi.org/10.1038/s41598-018-32996-w

Katono K et al (2014) Three-dimensional timeaveraged void fraction distribution measurement technique for BWR thermal hydraulic conditions using an X-ray CT system. J Nucl Sci Technol 52(3):388-395. https://doi.org/10.1080/00223131.2014.952699

Lockhart RW, Martinelli RC (1949) Proposed correlation of data for isothermal two-phase, two-component flow in pipes. Chem Eng Prog 45(1):39-48

Lorenzi M et al (2017) Novel experimental technique for 3D investigation of high-speed cavitating diesel fuel flows by X-ray micro computed tomography. Rev Sci Instrum 88(3):033706. https://doi. org/10.1063/1.4978795

Maurer S et al (2015) X-ray measurements of bubble hold-up in fluidized beds with and without vertical internals. Int J Multiph Flow 74:118-124. https://doi.org/10.1016/j.ijmultiphaseflo w.2015.03.009
McNeil DA (2000) Two-phase flow in orifice plates and valves. Proc Inst Mech Eng 214(5):743-756

McQuillan KW, Whalley PB (1984) The effect of orifices on the liquid distribution in annular two-phase flow. Int $\mathrm{J}$ Multiph Flow 10(6):721-729. https://doi.org/10.1016/03019322(84)90008-9

Perera K et al (2018) Comparison of gamma densitometry and electrical capacitance measurements applied to hold-up prediction of oil-water flow patterns in horizontal and slightly inclined pipes. Meas Sci Technol 29(6):065102. https://doi.org/10.1088/13616501/aab054

Roul MK, Dash SK (2012) Single-phase and two-phase flow through thin and thick orifices in horizontal pipes. Journal of Fluids Engineeringi. https://doi.org/10.1115/1.4007267

Salcudean M, Chun JH, Groeneveld DC (1983) Effect of flow pattern obstruction on void distribution in horizontal air-water flow. Int J Multiphase Flow 9(1):91-96. https://doi.org/10.1016/03019322(83)90009-5. http://www.sciencedirect.com/science/article/ pii/0301932283900095

Schubring D, Ashwood AC, Shedd TA (2008) Wall shear prediction for wavy and annular air-water two-phase flow. In: Proceedings of 16th International Conference on Nuclear Engineering, Vol. 3. pp 107-116. isbn: 0-7918-4816-7. https://doi.org/10.1115/ICONE $16-48110$

Sekoguchi K et al (1978) Film thickness in gas-liquid two-phase flow : 1st report, effect of a ring type obstacle inserted into tube. Bull JSME 21(155):869-876. https://doi.org/10.1299/jsme1958.21.869

Shedd TA, Newell TA (1998) Automated optical liquid film thickness measurement method. Rev Sci Instrum 69(12):4205-4213. https ://doi.org/10.1063/1.1149232

Tibiriçá CB, Júlio F, do Nascimento, Ribatski G (2010) Film thickness measurement techniques applied to micro-scale two-phase flow systems. Exp Thermal Fluid Sci 34(4):463-473. https://doi. org/10.1016/j.expthermflusci.2009.03.009

Wagner M, Hampel U, Bieberle M (2016) Correct averaging in transmission radiography: analysis of the inverse problem. Comput Phys Commun 202:196-203. https://doi.org/10.1016/j. cpc.2016.02.001

Yehuda Taitel, Dukler AE (1976) A model for predicting flow regime transitions in horizontal and near-horizontal gas-liquid flow. AlChE J 22:47. https://doi.org/10.1002/aic.690220105

Zboray R et al (2011) Cold-neutron tomography of annular flow and functional spacer performance in a model of a boiling water reactor fuel rod bundle. Nucl Eng Des 241(8):3201-3215. https://doi. org/10.1016/j.nucengdes.2011.06.029

Zboray R, Bolesch C, Prasser H-M (2018) Development of neutron and X-ray imaging techniques for nuclear fuel bundle optimization. Nucl Eng Des 336:24-33. https://doi.org/10.1016/j.nucen gdes.2017.04.035

Publisher's Note Springer Nature remains neutral with regard to jurisdictional claims in published maps and institutional affiliations. 